\title{
Voltage Balancing Method Using Phase-Shifted PWM for Stacked Multicell Converters
}

\author{
Amer M. Y. M. Ghias ${ }^{(1)} \quad$ Josep Pou $^{(1)(2)} \quad$ Vassilios G. Agelidis $^{(1)} \quad$ Mihai Ciobotaru $^{(1)}$ \\ (1) Australian Energy Research Institute \& School of Electrical Engineering and Telecommunications, \\ The University of New South Wales, UNSW Sydney, NSW 2052, Australia. \\ ${ }^{(2)}$ Terrassa Industrial Electronics Group \& Department of Electronic Engineering, \\ Technical University of Catalonia, Catalonia, Spain. \\ Email: amer.ghias@student.unsw.edu.au.
}

\begin{abstract}
This paper proposes an active voltage balancing method for stacked multicell converters (SMC) using phaseshifted pulse-width modulation, which is easy to implement and extend to high number of levels. The proposed method balances the voltages of the capacitors by modifying the duty cycle of each switch of the SMC using a proportional controller. The crossed effect between capacitor currents and duty cycles is considered and is used for optimal capacitor voltage balance. The performance of the proposed voltage balancing method is verified by simulation for different operating conditions, such as unbalanced linear loads, non-linear loads and load transients.

Index Terms-Multilevel converter; Stacked multicell converter; Capacitor voltage balancing; Pulse-width modulation.
\end{abstract}

\section{INTRODUCTION}

Multilevel converters allow higher voltage/power ratings, lower total harmonic distortion (THD), and lower losses, when compared with the conventional two-level converter [1], [2]. The most popular multilevel toplogies are the cascaded multi-modular converter [3], the modular multilevel converter (MMC) [4], the neutral-point-clamped (NPC) converter [5], and the flying capacitor (FC) converter [6]. Most of these topologies are well established by industry.

Multilevel topologies with more than five levels, require to store large amounts of energy, which strongly impacts on the converter size and price. Recently, hybrid multilevel converters has been introduced and are considered as competitive solution, since they require less energy storage when compared with the popular multilevel topologies [7]. One of the hybrid multilevel topology is the stacked multicell converter (SMC) which consist of two multilevel FC converters that are stacked together to generate multilevel voltage waveforms, as shown in Fig. 1. This $Y($ cell $) \times Z($ stage $)$ SMC allows higher voltage, with reduced FCs in the converter, when compared with the conventional multilevel FC converter.

Like the other multilevel topologies, the SMC also requires capacitor voltage balancing for the acceptable performance of the converter. In [9]-[15], phase-shifted pulse-width modulation (PS-PWM) was proposed, which provides natural voltage balance. However, natural voltage balance depends on the load conditions. The dynamics of the converter slow down with different types of load conditions. Some references in [9], [11], [12], [14] proposed a balance booster to achieve fast voltage balance dynamic. This balance booster consists of a passive $R L C$ filter, which introduces additional power losses.

There are a few active voltage balancing methods found in the technical literature [16]-[18]. In [16], a direct torque control method was proposed. This method regulates the FC voltage; however, no line-to-line voltage is shown and analyzed in the paper. Another active balancing method was proposed in [17], which makes use of a sliding mode observer. This method performs well as it does not require any voltage sensors. However, the method is complicated and requires a lot of computation. Finally, an active voltage balancing method which was proposed in [16], consists on evaluating a cost function for the redundant states using space vector modulation (SVM) in a four-level hybrid SMC. However, some limitations have been reported when operating with high modulation indices. The authors suggest increasing the number of voltage levels to extend the operating range of the converter, which is obviously not an optimal solution.

The majority of the solutions discussed above are complex from the implementation point of view and not easy to extend to higher number of levels. The main objective of this paper is to present a novel active voltage balancing method for the SMC that is efficient and can be easily extended to any number of levels. It is implemented using PS-PWM and is based on a proportional $(P)$ controller. The effects between the FC currents and the duty cycles of the switches are considered and used to optimize the voltage balancing process. Furthermore, the voltage balancing dynamic performance is very good. Although the proposed method has been applied to the sevenlevel $(3 \times 2)$ SMC, it can be easily extended to any number of levels.

The rest of the paper is organized as follows. Section II describes the operating principle of the SMC. Section III explains the proposed FC voltage balancing method. Section IV presents simulation results from a seven-level SMC to verify the effectiveness of the proposed method. Finally, the conclusions are summarized in Section V.

\section{Operating Principle of the SMC Converter}

Fig. 1 shows a circuit diagram of a three-phase sevenlevel SMC. It consist of three cells $(Y=3)$ of FC units, 


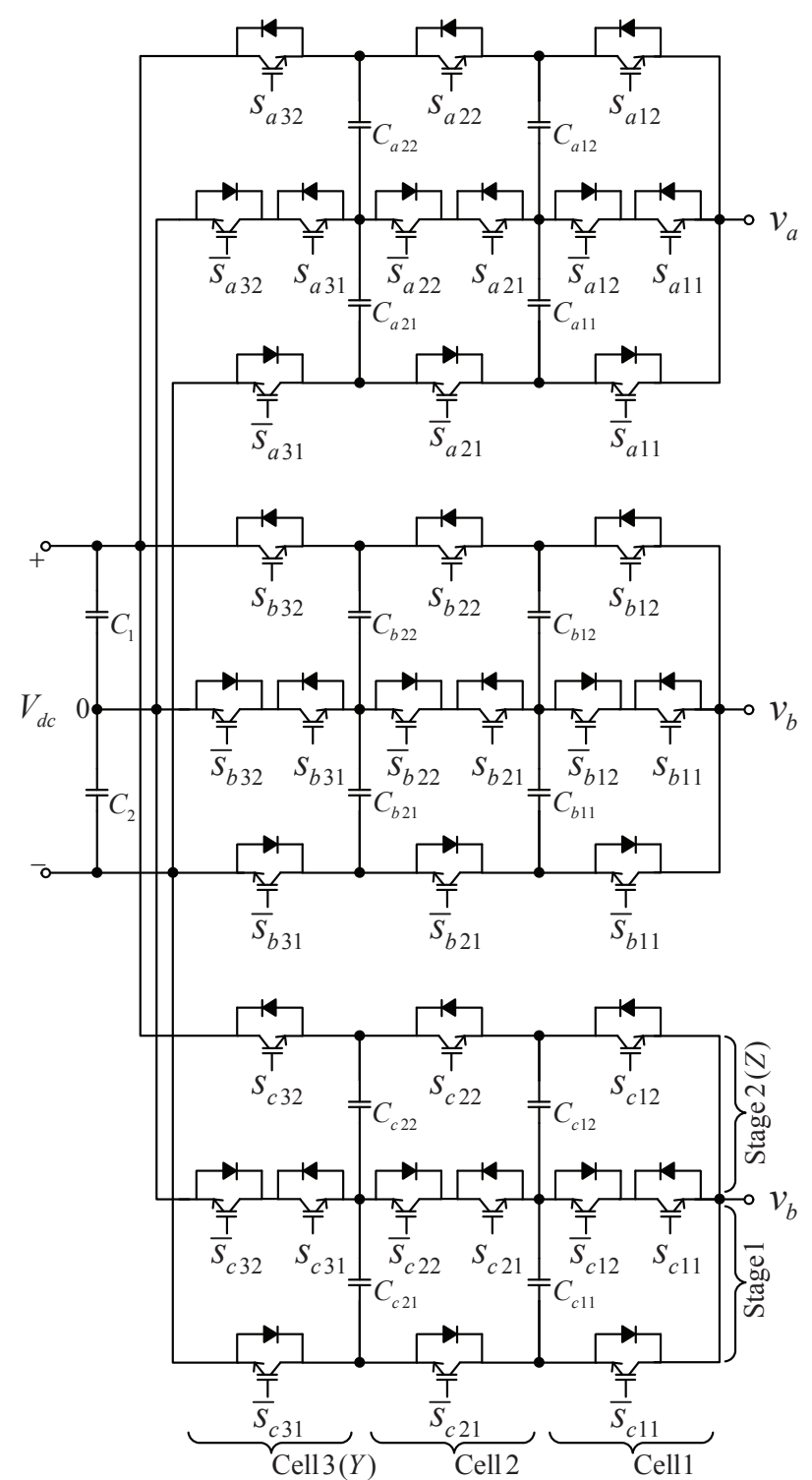

Fig. 1. Circuit diagram of a three-phase $3 \times 2$ SMC.

which are integrated to form two stages/stacks $(Z=2)$. It is called as $3 \times 2 \mathrm{SMC}$. The converter includes four FCs, the upper FCs, i.e, $C_{x 12}$ and $C_{x 22}$, are in the Stage 2, while the lower FCs $C_{x 11}, C_{x 21}$ are in the Stage 1, where the subscript $x$ is used for phase identification $x=\{a, b, c\}$. The dc bus consists of two capacitors, $C_{1}$ and $C_{2}$, each of them regulated to have a half of the dc-link voltage $\left(V_{d c} / 2\right)$. During normal operation, the mean voltages of the FCs $C_{x 11}$ and $C_{x 12}$ have to be maintained at $V_{d c} / 6$, whereas for FCs $C_{x 21}$ and $C_{x 22}$ have to be maintained at $V_{d c} / 3$. The output voltage $v_{x 0}$ can produce seven voltage levels $(3 \times 2+1)$, i.e. $0, V_{d c} / 6, V_{d c} / 3, V_{d c} / 2,2 V_{d c} / 3,5 V_{d c} / 6$, and $V_{d c}$. The switch control function are defined as $s_{x y z}$, where $y$ denotes the switch number corresponding to a particular cell in the phase-leg $x$ of the SMC converter $y=\{1, . ., Y\} \quad(Y=3)$, and $z$ defines a particular switch associated with the stage

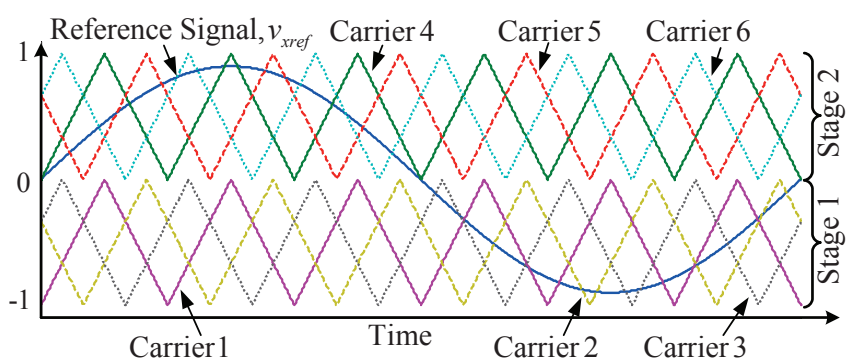

(a)

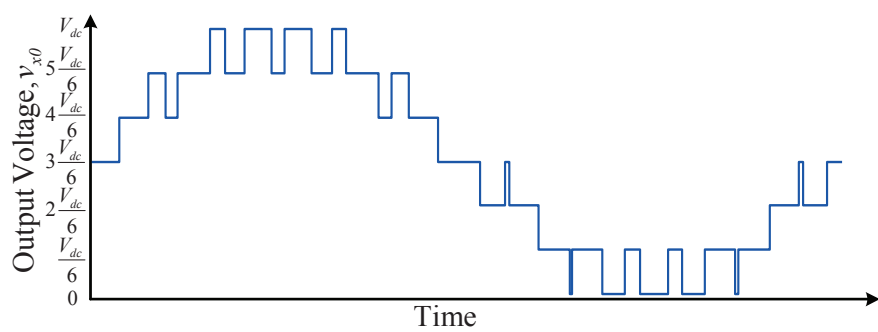

(b)

Fig. 2. PS-PWM technique for $3 \times 2$ SMC: (a) reference sinusoidal signal with six carriers and (b) output voltage.

$z=\{1, . ., Z\}(Z=2)$. The switch control functions can take two values $s_{x y z}=\{0,1\}$, meaning " 0 " and " 1 " that the switch is off and on, respectively. The switch pairs in each phase-leg $\left(s_{x y z}\right.$ and $\left.\bar{s}_{x y z}\right)$ operate in a complementary manner.

Fig. 2 shows a sinusoidal reference signal and the carrier signals using PS-PWM applied to a $3 \times 2$ SMC. In this converter, PS-PWM requires six carriers. The upper three carriers in Stage 2 are phase-shifted $120^{\circ}$ between consecutive carriers. The same characteristics apply to the three lower carriers in Stage 1. A sinusoidal reference signal $\left(v_{x r e f}\right)$ has been normalized to range in the interval $[-1,1]$ under linear modulation mode. It is compared with all six triangular carriers to define the voltage level that has to be generated at the output. Using this method, natural voltage balancing can be achieved. However, the voltage balancing process is usually slow and depends on the loading conditions. Therefore, an active balancing method is required to regulate the FC voltages at their desired levels with improved dynamics, especially under transient conditions and unbalanced linear/non-linear loads.

\section{Proposed Voltage Balancing Method}

Fig. 3(a) shows a general $Y \times Z$ SMC phase-leg chain. The proposed voltage balancing method is developed based on the analysis of a generic cell section of the SMC as shown in Fig. 3(b). In this analysis $Z=2$ is considered for simplicity. Assuming $v_{x \text { ref }}>0$, where the switches $s_{x y 1}$ and $s_{x(y+1) 1}$ are turned on. Therefore, the current through capacitor $C_{x y 2}$ is represented by [19]:

$$
i_{C x y 2}=\left(s_{x(y+1) 2}-s_{x y 2}\right) i_{x} .
$$

It can be observed that during $v_{x \text { ref }}>0$, the current through a capacitor is affected by the control signals associated 

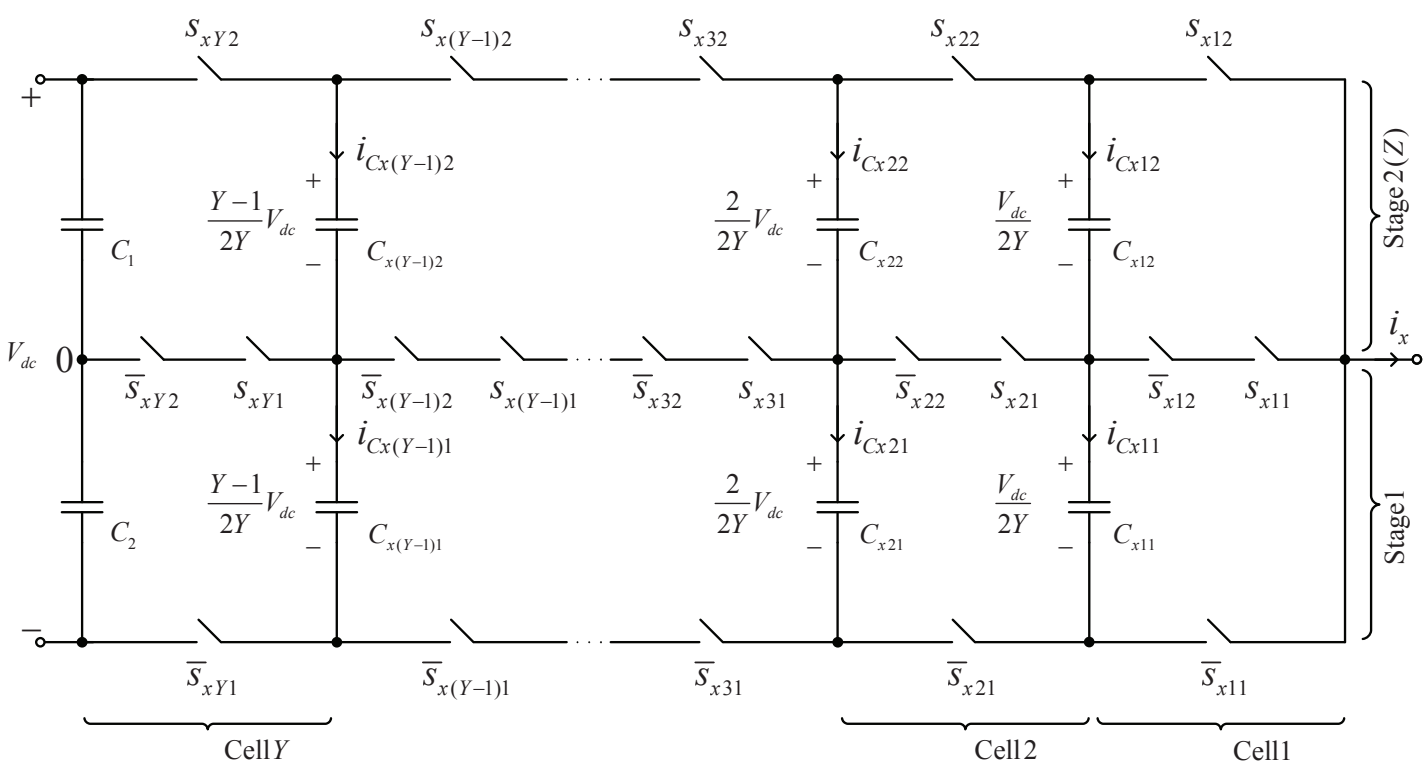

(a)

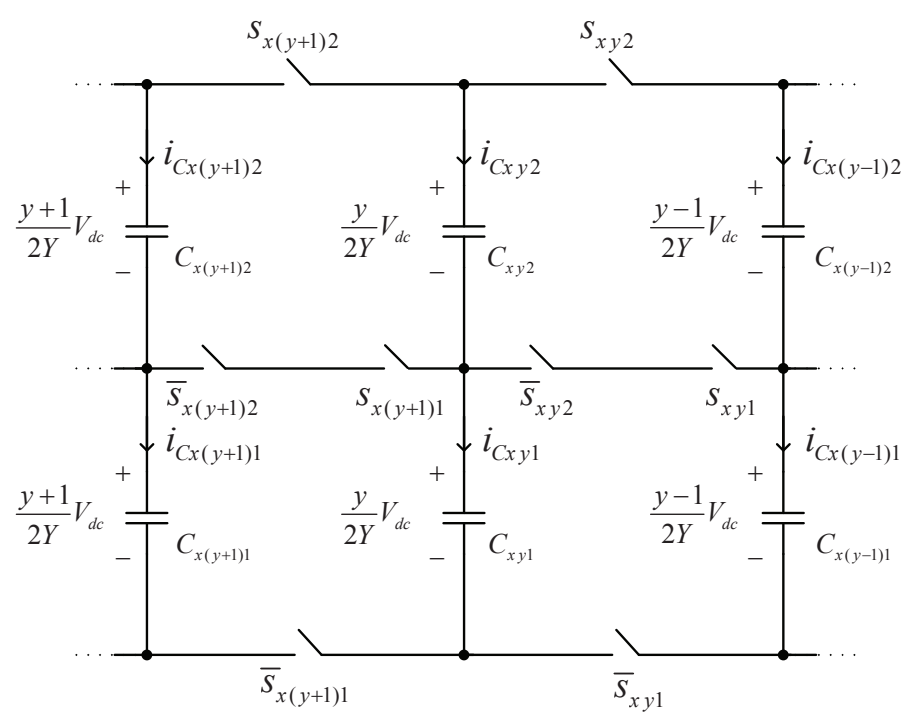

(b)

Fig. 3. One phase-leg of an SMC: (a) General $Y \times 2$ cell chain representation and (b) a section of the chain.

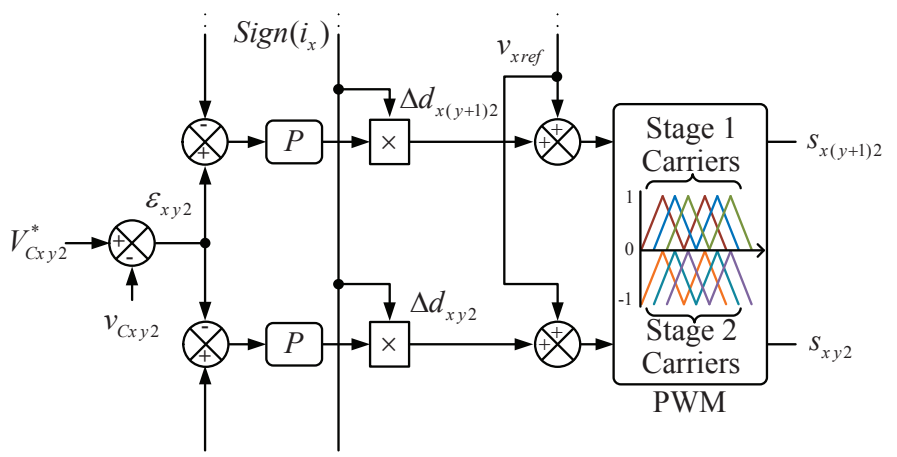

Fig. 4. Development of the proposed voltage balancing method based on (2). to the two adjacent switches. The locally-averaged representation of the capacitor current calculated over a switching period is:

$$
\bar{i}_{C x y 2}=\left(d_{x(y+1) 2}-d_{x y 2}\right) \bar{i}_{x}
$$

where $\bar{i}_{C x y 2}$ and $\bar{i}_{x}$ are the locally-averaged currents of the capacitor $C_{x y 2}$ and the output current, respectively, and $d_{x(y+1) 2}$ and $d_{x y 2}$ are the duty cycles of the switches $s_{x(y+1) 2}$ and $s_{x y 2}$ for Stage 2, respectively.

Assuming a positive output current $\left(i_{x}>0\right)$, (2) shows that by increasing the duty cycle $d_{x(y+1) 2}$ the locally-averaged current through the capacitor will increase, while the opposite effect will be produced if $d_{x y 2}$ is increased. If the voltage of the capacitor $C_{x y 2}$ is greater than its reference value, a negative current should be imposed to this capacitor. Therefore, 


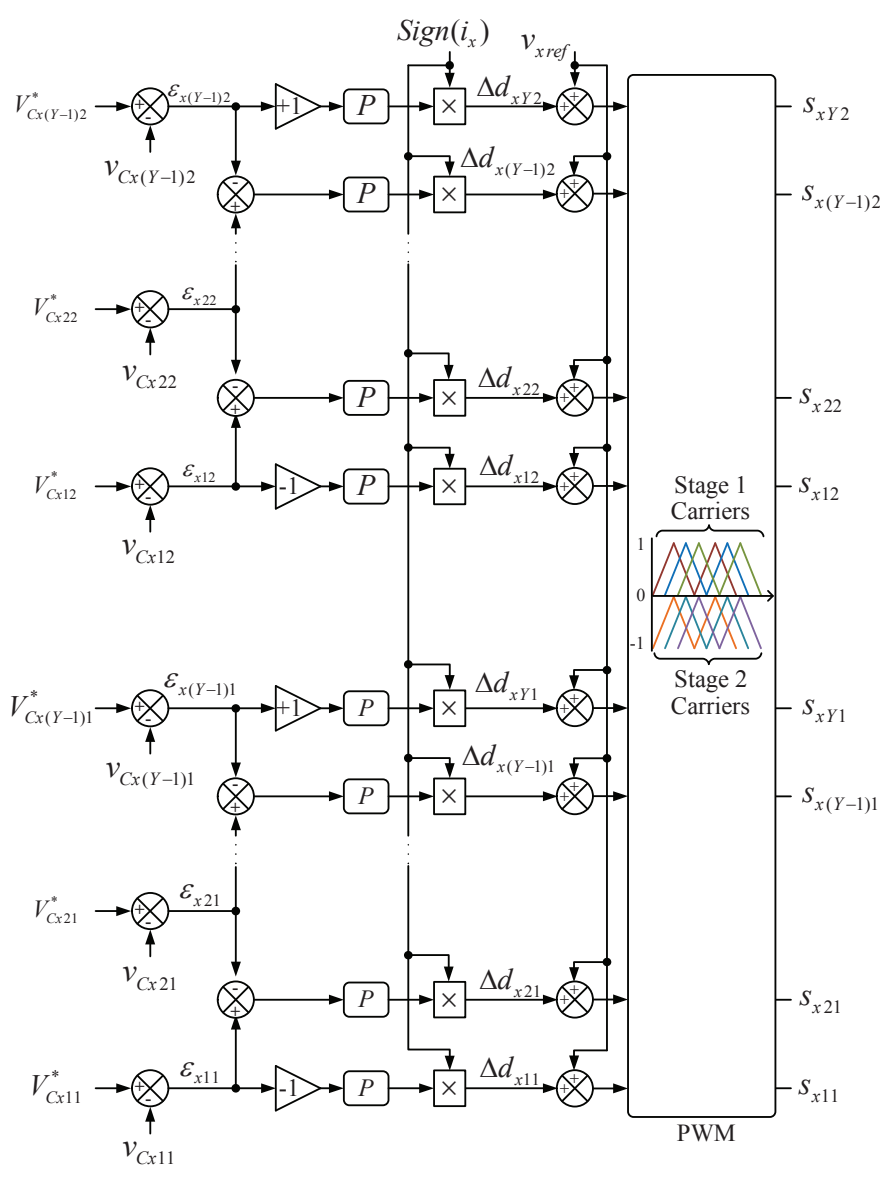

Fig. 5. Proposed voltage balancing method for a general $Y \times 2$ SMC.

the duty cycles $d_{x y 2}$ and $d_{x(y+1) 2}$ should be increased and decreased, respectively. On the other hand, if the output current is negative $\left(i_{x}<0\right)$, the duty cycles should be manipulated in the opposite direction to help for voltage balance. Based on this analysis, the control method for voltage balancing is developed for the upper cells located in the Stage 2. A similar analysis can be performed for the bottom capacitor $C_{x y 1}$ to achieve voltage balance, which is in the Stage 1. In this case $v_{x \text { ref }}<0$, and the switches $\bar{s}_{x(y+1) 2}$ and $\bar{s}_{x y 2}$ are turned on. Fig. 4 shows the proposed voltage balance method for a general case, where $\Delta d_{x y 2}$ and $\Delta d_{x(y+1) 2}$ are control magnitudes added to the reference signal $v_{x \text { ref }}$ to compensate for voltage balance. Fig. 5 shows the complete voltage balancing method for a $Y \times 2$ SMC.

Assuming $v_{x \text { ref }}>0$, the switches $s_{x y 1}$ and $s_{x(y+1) 1}$ are turned on, the voltage balancing dynamic of capacitor $C_{x} y 2$ can be analyzed based on:

$$
\bar{i}_{C x y 2}=C_{x y 2} \frac{d \bar{v}_{C x y 2}}{d t} \Leftrightarrow \frac{d \bar{v}_{C x y 2}}{d t}=\frac{\bar{i}_{C x y 2}}{C_{x y 2}} .
$$

From (2) and (3), one can obtain:

$$
\frac{d \bar{v}_{C x y 2}}{d t}=\frac{\bar{i}_{x}\left(d_{x(y+1) 2}-d_{x y 2}\right)}{C_{x y 2}},
$$

TABLE I

SMC CONVERTER PARAMETERS

\begin{tabular}{c|c}
\hline Circuit Parameter & Value \\
\hline DC Link Voltage $\left(V_{d c}\right)$ & $100 \mathrm{~V}$ \\
\hline Flying Capacitors $\left(C_{x 1}, C_{x 2}\right)$ & $400 \mu \mathrm{F}$ \\
\hline Load Resistance $(R)$ & $44 \Omega$ \\
\hline Load Inductance $(L)$ & $6 \mathrm{mH}$ \\
\hline Carrier Frequency $\left(f_{s}\right)$ & $2 \mathrm{kHz}$ \\
\hline Fundamental Frequency $(f)$ & $50 \mathrm{~Hz}$ \\
\hline Control Parameter $(P)$ & 0.04 \\
\hline
\end{tabular}

where,

$$
\begin{gathered}
d_{x(y+1) 2}=v_{x \text { ref }}+\Delta d_{x(y+1) 2}, \\
d_{x y 2}=v_{x \text { ref }}+\Delta d_{x y 2} .
\end{gathered}
$$

Assuming small variations around the operating point, using (5) and (6) in (4), one can obtain:

$$
\frac{\Delta \bar{v}_{C x y 2}}{\Delta t}=\frac{\bar{i}_{x}\left(\Delta d_{x(y+1) 2}-\Delta d_{x y 2}\right)}{C_{x y 2}} .
$$

The variations of the duty cycles are given by a proportional controller, as follows:

$$
\begin{gathered}
\Delta d_{x(y+1) 2}=\operatorname{sign}\left(i_{x}\right)\left(\varepsilon_{x y 2}-\varepsilon_{x(y+1) 2}\right) P, \\
\Delta d_{x y 2}=\operatorname{sign}\left(i_{x}\right)\left(\varepsilon_{x(y-1) 2}-\varepsilon_{x y 2}\right) P,
\end{gathered}
$$

where $\varepsilon_{x(y-1) 2}, \varepsilon_{x y 2}$, and $\varepsilon_{x(y+1) 2}$ are the voltage errors of the capacitors $C_{x(y-1) 2}, C_{x y 2}$, and $C_{x(y+1) 2}$ at Stage 2 , respectively, and $P$ is the proportional control parameter. $\operatorname{sign}\left(i_{x}\right)$ is the sign of the output current defined as 1 and -1 when $i_{x}$ is positive and negative, respectively. Substituting (8) and (9) into (7):

$$
\frac{\Delta \bar{v}_{C x y 2}}{\Delta t}=\frac{\left|\bar{i}_{x}\right| P\left(2 \varepsilon_{x y 2}-\varepsilon_{x(y+1) 2}-\varepsilon_{x(y-1) 2}\right)}{C_{x y 2}} .
$$

Equation (10) defines the balancing dynamic of the proposed voltage control for $Y \times 2 \mathrm{SMC}$ when $v_{x}$ ref $>0$ and can be used to tune the controller gain parameter $P$ to achieve a satisfactory converter performance. A similar kind of analysis can be performed for $v_{x \text { ref }}<0$, when switches $\bar{s}_{x(y+1) 2}$ and $\bar{s}_{x y 2}$ are turned on, for the voltage balance of the bottom capacitor $C_{x y 1}$ in Stage 1.

\section{Performance Evaluation}

Simulation tests are performed on a three-phase $3 \times 2$ SMC converter as shown in Fig. 1. The converter has been simulated using the MATLAB/Simulink [20] and PLECS Toolbox [21]. The parameters of the converter are shown in Table I.

The dynamic behavior of the proposed voltage balancing method is shown in Fig. 6. In this test, the SMC is operating over a linear unbalanced $R L$ load $\left(R_{a}=70.4 \Omega, R_{b}=\right.$ $\left.17.6 \Omega, R_{c}=44 \Omega\right)$. The line-to-line voltage $v_{a b}$ and the capacitor voltages $\left(v_{C a 11}, v_{C a 12}, v_{C a 21}\right.$, and $\left.v_{C a 22}\right)$ are shown in Fig. 6(a). In this simulation, the initial capacitor voltages are set to $v_{C a 11}=6 \mathrm{~V}, v_{C a 12}=24 \mathrm{~V}, v_{C a 21}=28 \mathrm{~V}$, 


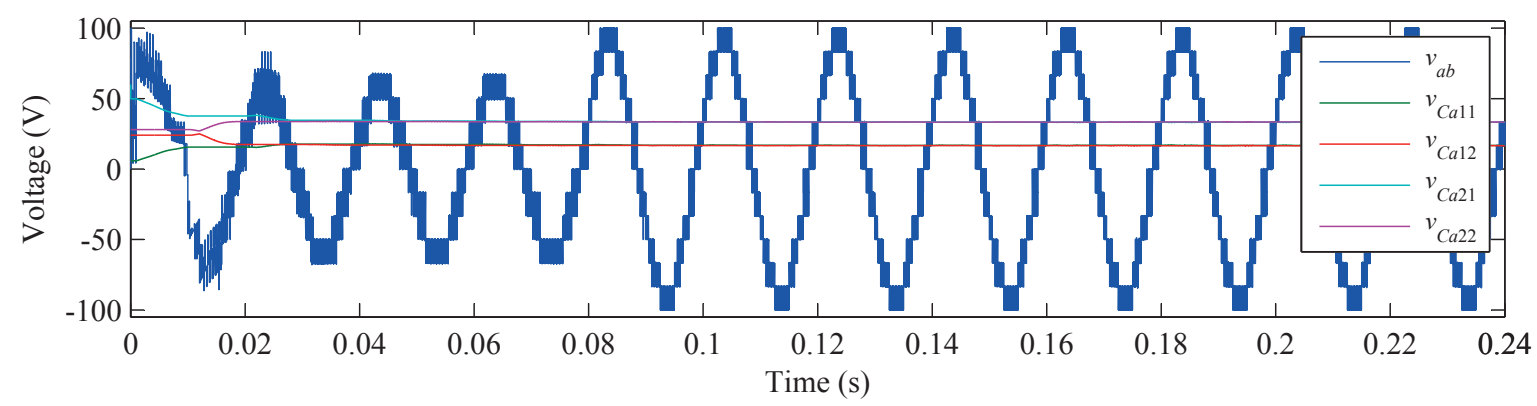

(a)

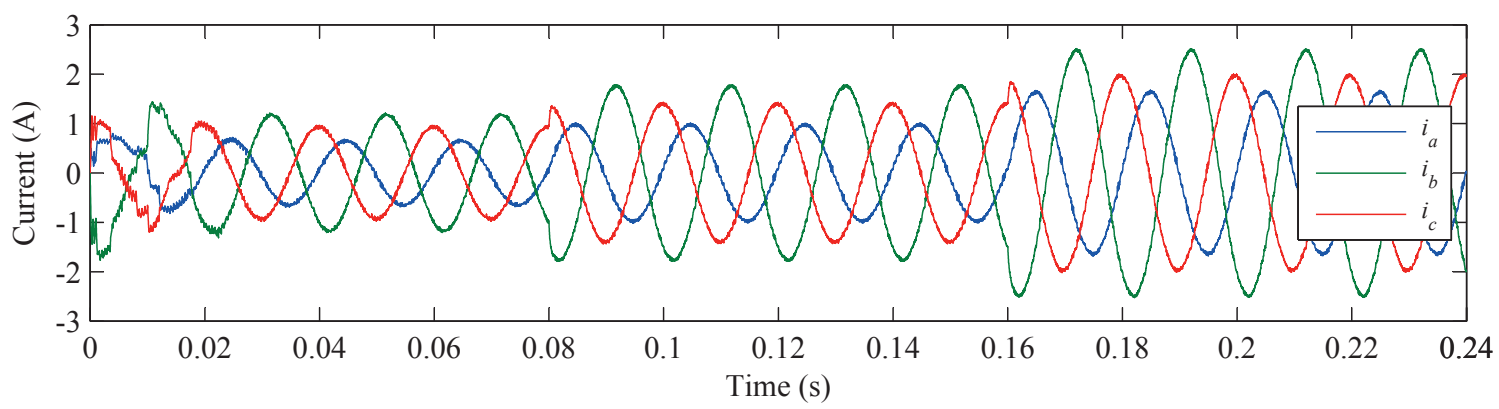

(b)

Fig. 6. $3 \times 2$ SMC operating over an unbalanced linear load. A step change in the modulation index from $m=0.6$ to $m=0.9$ occurs at $80 \mathrm{~ms}$, and at $160 \mathrm{~ms}$ a three-phase Y-connected resistive load is added in parallel $\left(R_{x}=88 \Omega\right)$ : (a) line-to-line voltage $\left(v_{a b}\right)$ and $\mathrm{FC}$ voltages $\left(v_{C a 11}, v_{C a 12}, v_{C a 21}\right.$, and $\left.v_{C a 22}\right)$, and (b) output currents $\left(i_{a}, i_{b}\right.$, and $\left.i_{c}\right)$.

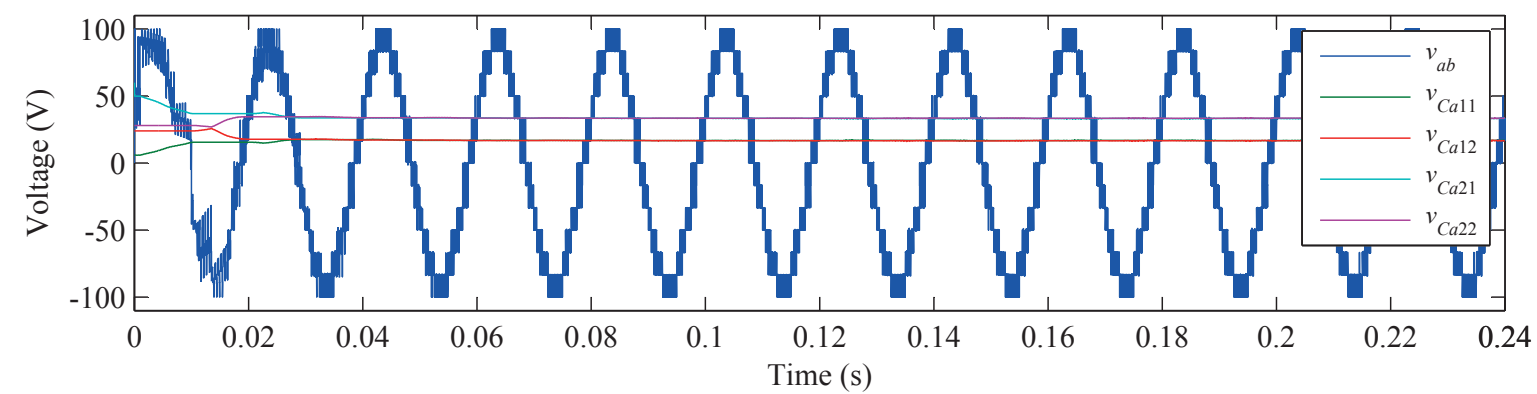

(a)

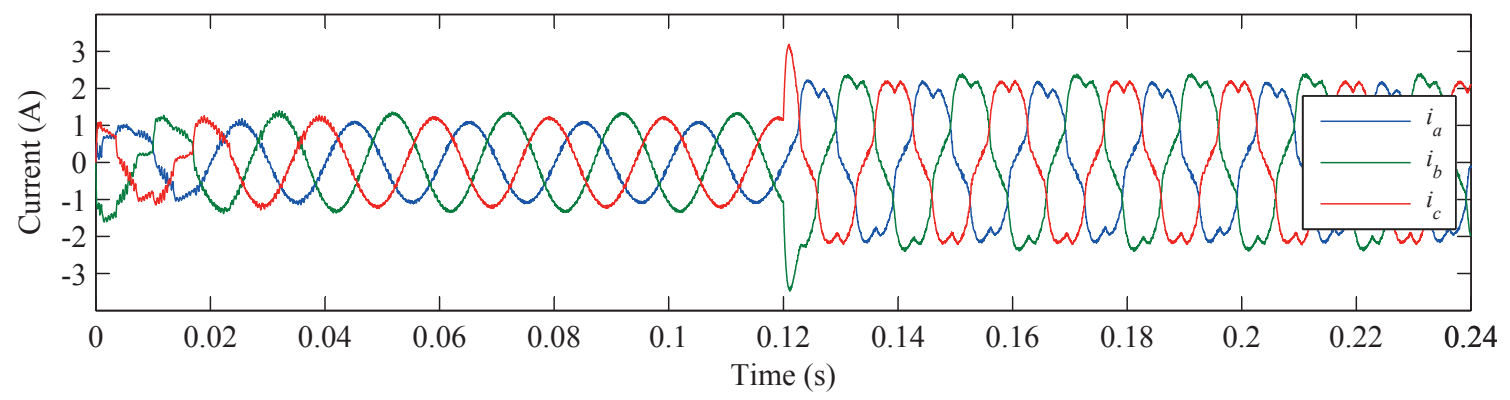

(b)

Fig. 7. $3 \times 2$ SMC operating over an unbalanced linear load and at $120 \mathrm{~ms}$ an non-linear load is added: (a) line-to-line voltage ( $\left.v_{a b}\right)$ and FC voltages $\left(v_{C a 11}, v_{C a 12}, v_{C a 21}\right.$, and $\left.v_{C a 22}\right)$, and (b) output currents $\left(i_{a}, i_{b}\right.$, and $\left.i_{c}\right)$. 
$v_{C a 22}=60 \mathrm{~V}$ and regulated to the desired voltages, i.e. 16.67 $\mathrm{V}, 16.67 \mathrm{~V}, 33.33 \mathrm{~V}$, and $33.33 \mathrm{~V}$, respectively, in about 30 ms. It can be observed that the proposed voltage balancing method is capable of maintaining the capacitor voltages at the reference value under this unbalanced condition. There is a step change in the modulation index from $m=0.6$ to $m=0.9$ at $80 \mathrm{~ms}$, and later at $160 \mathrm{~ms}$, a three-phase Y-connected resistive load is added in parallel $\left(R_{x}=88 \Omega\right)$. Observe that during the transients the voltages in the FCs remain unaffected. In Fig. 6(b), the load currents increase as expected during these transients. The proposed voltage balancing method proves to be robust under unbalanced loads and transients. Furthermore, although the proposed voltage balancing method is based on a proportional controller, the capacitor voltages are properly regulated at the reference values with no zero-order errors in the steady-state. This is because no control action is required $\left(\Delta d_{x y 1}=0\right.$ and $\Delta d_{x y 2}=0$ for $\left.y=\{1,2,3\}\right)$ when the capacitor voltages are at the reference values.

In Fig. 7, the converter is tested against a non-linear load. Initialy, the converter operates over a linear unbalanced $R L$ load $\left(R_{a}=44 \Omega, R_{b}=35.2 \Omega, R_{c}=52.8 \Omega\right)$ with a modulation index of $m=0.9$. At $120 \mathrm{~ms}$, a non-linear load consisting of a three-phase diode rectifier with a filter capacitor of $30 \mu \mathrm{F}$ and a load resistor of $88 \Omega$ is added. It can be observed in Fig. 7(a), that the capacitor voltages are maintained to the desired references. The load currents shown in Fig. 7(b), are highly distorted as expected, but no effects on the FCs is seen. Hence, the proposed voltage balancing method is quite robust, as the capacitor voltages are maintained at their reference values under such a non-linear load and unbalanced conditions.

\section{CONCLUSION}

A new voltage balancing method for SMC operating with PS-PWM has presented which ensures the acceptable performance of the converter by maintaining the capacitor voltage levels. The method has been formulated for a $Y \times 2$ SMC and is tested on $3 \times 2$ SMC which produces seven levels. The proposed method is based on a proportional controller which is able to remove the steady-state errors. This is because when the capacitor voltages are at their reference values, i.e. the voltage errors are zero, no control action is required. It can regulate the capacitor voltages to their reference values, even under unbalanced load, non-linear load and transients. Moreover, it is simple and easy to implement in any $Y \times Z$ SMC configuration.

\section{ACKNOWLEDGMENT}

This work has been supported by the University of New South Wales, Australia Energy Research Institute and the School of Electrical engineering and Telecommunications.

It has also been supported by the Ministerio de Economa y Competitividad of Spain under project ENE2012-36871-C0201 .

\section{REFERENCES}

[1] J. S. Lai and F. Z. Peng, "Multilevel converters - A new breed of power converters," IEEE Trans. Ind. Appl., vol. 32, no. 3, pp. 509-517, May/Jun. 1996.

[2] S. Kouro, M. Malinowski, K. Gopakumar, J. Pou, L. G. Franquelo, B. Wu, J. Rodriguez, M. A. Perez, and J. I. Leon, "Recent advances and industrial applications of multilevel converters," IEEE Trans. Ind. Electron., vol. 57, no. 8, pp. 2553-2580, Aug. 2010.

[3] F. Z. Peng, J. S. Lai, J. W. McKeever, and J. VanCoevering, "A multilevel voltage-source inverter with separate dc sources for static VAr generation," IEEE Trans. Ind. Appl., vol. 32, no. 5, pp. 1130-1138, Sep./Oct. 1996.

[4] A. Lesnicar and R. Marquardt, "An innovative modular multilevel converter topology suitable for a wide power range," in Proc. IEEE Power Tech Conference, 23-26 June 2003, vol. 3, pp. 6.

[5] A. Nabae, I. Takahashi, and H. Akagi, "A new neutral-point-clamped PWM inverter," IEEE Trans. Ind. Appl., vol. IA-17, no. 5, pp. 518-523, Sep./Oct. 1981.

[6] T. A. Meynard and H. Foch, "Multi-level conversion: High voltage choppers and voltage-source inverters," in Proc. 23rd Annual IEEE Power Electronics Specialists Conference (PESC), 29 Jun-3 Jul 1992, vol. 1, pp. 397-403.

[7] T. A. Meynard, H. Foch, F. Forest, C. Turpin, F. Richardeau, L. Delmas, G. Gateau, and E. Lefeuvre, "Multicell converters: derived topologies," IEEE Trans. Ind. Electron., vol. 49, no. 5, pp. 978-987, Oct 2002.

[8] G. Gateau, T. A. Meynard, and H. Foch, "Stacked multicell converter (SMC): properties and design," in Proc. 32nd Annual IEEE Power Electronics Specialists Conference (PESC), 2001, vol. 3, pp. 1583-1588.

[9] L. Delmas, G. Gateau, T. A. Meynard, and H. Foch, "Stacked multicell converter (SMC): control and natural balancing," in Proc. 33rd Annual IEEE Power Electronics Specialists Conference (PESC), 2002, vol. 2, pp. 689-694.

[10] J. Aguillon-Garcia, J. M. Fernandez-Nava, and P. Bauelos-Sanchez, "Unbalanced voltage effects on a single phase multilevel inverter due to control strategies," in Proc. IEEE 26th Annual International Telecommunications Energy Conference, 19-23 Sept. 2004, pp. 140-145.

[11] B. P. McGrath, T. Meynard, G. Gateau, and D. G. Holmes, "Optimal modulation of flying capacitor and stacked multicell converters using a state machine decoder," IEEE Trans. Power Electron., vol. 22, no. 2, pp. 508-516, March 2007.

[12] A. K. Sadigh, S. H. Hosseini, M. Sabahi, and G. B. Gharehpetian, "Double flying capacitor multicell converter based on modified phaseshifted pulsewidth modulation," IEEE Trans. Power Electron., vol. 25, no. 6, pp. 1517-1526, June 2010.

[13] J. M. F. Nava and P. B. Sanchez, "Stacked multicell converter controlled by DSP," in Proc. IEEE International Conference on Electronics, Communications and Computers, 16-18 Feb. 2004, pp. 69-74.

[14] S. H. Hosseini and M. Sadeghi, "Reduced stacked multicell converter with minimized stored energy of flying capacitors," in Proc. 2nd IEEE PES International Conference and Exhibition on Innovative Smart Grid Technologies (ISGT Europe), 5-7 Dec. 2011, pp. 1-5.

[15] M. Ben Smida and F. Ben Ammar, "Modeling and DBC-PSC-PWM control of a three-phase flying-capacitor stacked multilevel voltage source inverter," IEEE Trans. Ind. Electron., vol. 57, no. 7, pp. 2231-2239, Jul. 2010.

[16] A. Bennani, T. Meynard, and G. Gateau, "Direct torque control for stacked multicell (SMC) VSI fed induction machine," EPE Conference on Power Electronics and Applications, 2005, pp. 1-10.

[17] A. M. Lienhardt, G. Gateau, and T. A. Meynard, "Digital sliding-mode observer implementation using FPGA," IEEE Trans. Ind. Electron., vol. 54, no. 4, pp. 1865-1875, Aug. 2007.

[18] A. Leredde and G. Gateau, "Control of the DC link capacitor voltage on a new four-level SMC based topology," in Proc. IEEE International Symposium on Industrial Electronics (ISIE), 27-30 June 2011, pp. 18511856.

[19] A. M. Y. M. Ghias, J. Pou, M. Ciobotaru, and V. G. Agelidis, "Voltage balancing method for the multilevel flying capacitor converter using phase-shifted PWM," in Proc. IEEE International Confeence on Power and Energy (PECon), pp. 274-279, 2-5 Dec. 2012.

[20] Matlab/Simulink, http://www.matlab.com.

[21] PLECS, http://www.plexim.com. 